\title{
Cerebellar Development and Neurogenesis in Zebrafish
}

Jan Kaslin ${ }^{1 *}$ and Michael Brand ${ }^{2 *}$

1) Australian Regenerative Medicine Institute, Monash University, Innovation Walk 15, Clayton, Victoria, 3800, Melbourne, Australia

2) Biotechnology Center and Center for Regenerative Therapies Dresden, Dresden University of Technology, Tatzberg 47, 01307, Germany

*Corresponding authors: jan.kaslin@monash.edu, michael.brand@biotec.tu-dresden.de

Keywords: zebrafish, teleost, fish, adult neurogenesis, mutant, screening, eurydendroid cell, genetic model, cerebellar development, morphogenesis, mid-hindbrain-boundary, isthmic organizer, in vivo imaging

\section{Introduction}

Cerebellar organization and function have been studied in numerous species of fish. Fish models such as goldfish and weakly electric fish have led to important findings about the cerebellar architecture, cerebellar circuit physiology and brain evolution. However, most of the studied fish models are not well suited for developmental and genetic studies of the cerebellum. The rapid transparent ex utero development in zebrafish allows direct access and precise visualization of all the major events in cerebellar development. The superficial position of the cerebellar primordium and cerebellum further facilitates in vivo imaging of cerebellar structures and developmental events at single cell resolution. Furthermore, zebrafish is amenable to high-throughput screening techniques and forward genetics because of its fecundity and easy keeping. Forward genetics screens in zebrafish have resulted in several isolated cerebellar mutants and substantially contributed to the understanding of the genetic networks involved in hindbrain development (Bae et al. 2009; Brand et al. 1996). Recent developments in genetic tools, including the use of site specific recombinases, efficient transgenesis, inducible gene expression systems, and the targeted genome lesioning technologies TALEN and Cas9/CRISPR has opened up new avenues to manipulate and edit the genome of zebrafish (Hans et al. 2009; Scott 2009; Housden et al. 2016; Li et al. 2016) . 
These tools enable the use of genome-wide genetic approaches, such as enhancer/exon traps and cell specific temporal control of gene expression in zebrafish. Several seminal papers have used these technologies to successfully elucidate mechanisms involved in the morphogenesis, neurogenesis and cell migration in the cerebellum (Bae et al. 2009; Chaplin et al. ; Hans et al. 2009; Volkmann et al. ; Volkmann et al. 2008). In addition, the use of genetically encoded sensors and probes that allows detection and manipulation of neuronal activity using optical methods have open up new means to study the physiology and function of the cerebellum (Simmich et al. 2012; Matsui et al. 2014). Taken together, these features have allowed zebrafish to emerge as a complete model for studies of molecular, cellular and physiological mechanisms involved in cerebellar development and function at both cell and circuit level.

\subsection{The cerebellar anatomy and architecture}

The general organization and cellular architecture of the cerebellum is highly conserved in vertebrates. The cerebellum of all jawed vertebrates consists of a major lobe, the corpus cerebelli (cerebellar corpus) and two bilateral lobes, the auricle (flocculus in tetrapods, also known as the vestibulocerebellum, (Altman and Bayer 1997), Figure 1). The auricle is a specialized part of the corpus cerebelli that primarily receives input from the vestibular system. The architecture of the zebrafish and teleost fish cerebellum is highly similar to other vertebrates but there are some notable differences. The most striking differences are the lack of deep cerebellar nuclei and a well defined white matter. Furthermore, teleost fish have additional precerebellar and cerebelloid structures (see below).

The cerebellum of teleost fish can be divided in three major parts, the valvula cerebelli, the corpus cerebelli (cerebellar corpus) and the vestibulolateral lobe (Figure 2, (Finger 1983; Meek 1998; Wullimann 1997)). The eminentia granularis and the caudal lobe together form the vestibulolateral lobe that has been suggested to be homologous to the auricle of other vertebrates (Wullimann 1997). The cerebellar corpus in zebrafish consists of a single folia and it has an anterior extension, the valvula cerebelli. The valvula cerebelli is extending into the tectal ventricle below the optic tectum. The cerebellar corpus is laterally flanked by the eminentia granularis and posteriorly by the caudal lobe. 
In addition, teleost fish and zebrafish have extra structures associated to the cerebellum, such as the, cerebelloid structures (cerebellar-like) and the additional pre-cerebellar nuclei. These structures are not found in other vertebrates. The pre-cerebellar nuclei send the majority of their projections to the cerebellum and are therefore a part of the cerebellar circuitry in teleosts. Zebrafish has two precerebellar nuclei, the nucleus valvula lateralis and the nucleus paracommissuralis (Figure 1). The nucleus valvula lateralis is found in the tegmentum beneath the cerebellar corpus and its main efferents target is granule cells in the corpus cerebelli and valvulae cerebelli. The nucleus paracommissuralis is found in the midbrain, dorsal to the posterior commissure. The nucleus paracommissuralis receives input from telecephalon and sends major output to the cerebellum and torus longintudinalis (Volkmann et al. ; Butler A. 2005).

Cerebelloid structures are brain structures that are architecturally thought to be very similar to the cerebellum, although they are spatially well separated from the cerebellum. Cerebelloid structures are found in all vertebrate lineages except reptiles and birds (Bell 2002). Like the cerebellum, the cerebelloid structures process sensory signals, receive input from the periphery to the deep layers and parallel fiber input to the molecular layer. More in depth discussion on evolution of cerebellum-like structures and their function in vertebrates is found in excellent reviews on the topic (Bell 2002; Bell et al. 2008; Devor 2000). In zebrafish two cerebelloid structures and systems are found. In the hindbrain the medial octavolateral nucleus, eminentia granularis and the cerebellar crest (crista cerebellaris) form one cerebelloid structure. Purkinje-like cells in the medial octavolateral nucleus extend their apical dendrites to the molecular layer of the cerebellar crest. The cerebellar crest is a molecular fiber layer that is continuous with the most caudal part of the corpus cerebelli. The molecular layer of the cerebellar crest consists of parallel fibers that are originating from granule cells in the eminentia granularis. The exact function of the medial octavolateral nucleus-eminentia granularis-cerebellar crest system is unknown but it is likely involved in processing input from mechanical lateral line sensory system and acoustic centers (Bell 2002). The torus longintudinalis together with the optic tectum forms a second cerebelloid structure in zebrafish. The fiber rich superficial marginal layer in the optic tectum serves as a molecular layer (optic tectum marginal layer) and the marginal layer receives parallel fiber input from the torus longintudinalis. Principal neurons of the circuit known as type I neurons, may serve Purkinje-like cell functions and are found in the deeper layers of the optic tectum (Bell 2002; Meek 1983). The torus longintudinalis-optic tectum circuit may be involved in regulation and 
prediction of visuomotor response, since granule cells in the torus longintudinalis respond to visual stimuli as well as to stimuli that evokes eye movements (Gibbs and Northmore 1996; Northmore 1983). Furthermore, the torus longintudinalis may be involved in the regulation of the dorsal light response (Butler A. 2005).

\subsection{Cerebellar cell layers, cell types and circuitry}

The general vertebrate cerebellum consists of a three-layered cortex with an underlying white matter (Altman and Bayer 1997). This three layered arrangement is well recognizable in the valvula and corpus cerebelli in zebrafish (Figure 2). The most superficial layer, the molecular layer is rich in dendrites and unmyelinated axons but inhabits very few cells. A thin intermediate layer consisting of a single row of Purkinje neurons borders the thick internal granule cell layer that mainly consists of densely packed granule cells. However, in zebrafish the eminentia granularis and the caudal lobe consists of a single granule cell layer. An anatomically well recognizable layer of white matter consisting of incoming and outgoing fibers to the cerebellum is detected below the cerebellar corpus in tetrapods. However, zebrafish and other non-tetrapods anatomically lack a well-defined white matter beneath the cerebellum but have equivalent circuitry (see below).

The cerebellum contains relatively few cell types with distinct morphological, molecular and physiological characteristics (Figure 3). The cerebellar neurons can be divided into two major categories based on their function as inhibitory or excitatory. Inhibitory neurons use the gamma-butyric acid (GABA) or glycin as their main neurotransmitter, while excitatory neurons use glutamate as their main neurotransmitter. In zebrafish and teleost fish three distinct subtypes of inhibitory neurons have been found in the cerebellar cortex: stellate, Golgi and Purkinje cells. The stellate cells are scattered in the molecular cell layer of teleost fish, while Golgi cells primarily are found in the granule cell layer (Figure 3, (Butler A. 2005; Delgado and Schmachtenberg 2008; Kaslin et al. 2009; Meek et al. 2008). Stellate cells extend axons parallel to the parallel fibers and their axons end on the dendrites of Purkinje cells, while Golgi cell axons terminate on granule cell dendrites. Stellate and Golgi cells both receive input from parallel fibers. In addition, mossy fibers innervate the dendrites of Golgi cells. 
Purkinje cells extend prominent dendrites into the molecular layer and receive input from climbing fibers, granule cells and stellate cells. In most vertebrates the Purkinje cell is the sole cell type that projects outside the cerebellum to the deep cerebellar nuclei. The deep cerebellar nuclei are located in the white matter beneath the cerebellum. In zebrafish and other teleost fish this is different. Firstly, teleost fish have an additional efferent cell type in the cerebellar cortex, the eurydendroid cell (Butler A. 2005; Nieuwenhuys et al. 1974). In zebrafish and other teleost fish the Purkinje cell directly projects to the eurydendroid cells that are located in close by in the same layer (Alonso et al. 1992; Bae et al. 2009; Meek 1992). Secondly, teleost fish lack deep cerebellar nuclei. This may be a unique feature of the teleost fish since lampreys and sharks have at least one deep cerebellar nucleus (Butler A. 2005). However, the teleost eurydendroid cells directly innervate similar targets in the thalamus, brain stem and spinal cord (see below for details) as the deep cerebellar nuclei of other vertebrates and may thus have an equivalent function (Butler A. 2005; Bae et al. 2009; Ikenaga et al. 2005; Murakami and Morita 1987). The deep cerebellar nuclei of tetrapods contain both GABAergic and glutamergic cells. However, the eurydendroid cells in teleost fish appear to be exclusively glutamergic further highlighting the unique characteristics of teleosts in this respect (Bae et al. 2009; Hoshino 2006; Hoshino et al. 2005; Ikenaga et al. 2005, 2006; Machold and Fishell 2005; Wang et al. 2005).

Similar to other vertebrates abundant glutamergic granule cells are found in the granule cell layer in zebrafish (Bae et al. 2009; Kaslin et al. 2009). In the granule cell layer dendrites from granule cells together with Golgi cell axons and mossy fiber terminals form a specialized synaptic structure named the glomerulus. The granule cells gives rise to parallel fibers that ascend through the molecular layer where they synapse on the dendritic branches of Purkinje cells and stellate cells. The parallel fibers in teleost fish do not bifurcate in contrast to other vertebrates (Butler A. 2005). Excitatory unipolar brush cells have primarily been reported in mammals chick and mormyrid fish (Meek et al. 2008; Mugnaini et al. ; Takacs et al. 1999). Unipolar brush cells have not yet been identified in zebrafish. Additional inhibitory cerebellar cell types such as basket, Lugaro and candelabrum cells have been found in other vertebrates but have not been identified in teleost fish so far (Ambrosi et al. 2007). Basket cells may be a tetrapod specific cell type since they have not yet been identified in fish (Butler A. 2005), while Lugaro and candelabrum cells seem to be a mammalian specific cell types (Ambrosi et al. 2007; Crook et al. 2006; Laine and Axelrad 1994). 


\subsection{Cerebellar afferents and efferents}

The vertebrate cerebellum receives afferent input from two principal sources, mossy and climbing fibers (Figure 2 B,(Altman and Bayer 1997)). In zebrafish the climbing fibers originate in the inferior olive in the caudal hindbrain and innervate the dendritic branches of Purkinje cells. In teleost fish the climbing fibers predominately terminate on the soma and the proximal dendrites of Purkinje neurons (Folgueira et al. 2006; Pouwels 1978; Wullimann and Northcutt 1988; Xue et al. 2008). Climbing fibers and their innervations of Purkinje cells were recently identified in zebrafish by using transgenic lines that specifically label neurons in the inferior olive (Figure 3 B, (Bae et al. 2009)).

Similar to other vertebrates the mossy fiber-like pathway in teleost fish originates from multiple sources such as the spinal cord, reticular formation and tegmentum (Figure 3B). Retrograde tracing experiments in different teleost species have identified mossy fiber-like input to the corpus cerebelli and valvulae cerebelli (Figure 2 B, (Finger 1978; Folgueira et al. 2006; Volkmann et al. ; Wullimann and Northcutt 1988, 1989). The mossy fiber-like pathway in teleosts originates from multiple sources such as the spinal cord, sensory medulla, reticular formation, lateral reticular nucleus, locus coeruleus, pretectum, nucleus isthmi, accessory optic system, nucleus valvulae, dorsal tegmental nucleus and nucleus paracommissuralis (Folgueira et al. 2006; Kani et al. ; Volkmann et al. ; Wullimann and Northcutt 1988, 1989). Regional differences in fiber input to the valvuvla, corpus cerebelli and caudal lobe have been reported (Folgueira et al. 2006; Wullimann and Northcutt 1988, 1989). Systematic retrograde tracing experiments have not yet been undertaken in zebrafish. However, in agreement with above mentioned studies in other teleosts, mossy fiber-like input from several precerebellar nuclei has recently been reported in larval and juvenile zebrafish (Bae et al. 2009; Kani et al. ; Volkmann et al.).

The deep cerebellar nuclei in tetrapods innervate diverse nuclei in the thalamus, brain stem and spinal cord. Similarly, the cerebellar output from eurydendroid cells in teleosts directly innervates targets such as the ventral thalamus, pretectal nuclei, tegmental nuclei, motor and premotor centers such as the oculomotor nucleus, nucleus ruber, nucleus of the medial longintudinal fascicle, reticular formation and hypothalamic nuclei (Figure 3 B, (Finger 1978; Folgueira et al. 2006; Ikenaga et al. 2002; Ito and Yoshimoto 1990; Wullimann and Northcutt 
1988). Tracing experiments to elucidate the cerebellar efferents in detail have not yet been undertaken in zebrafish.

\section{Cerebellar development}

The initial phase of midbrain and cerebellar development in vertebrates depends on the formation and function of the isthmic organizer which lies at the midbrain-hindbrain boundary (MHB, Figure 3). The MHB organizer formation and maintenance is defined by an intricate cascade of genetic interactions that are marked by complex temporal and spatial patterns of gene expression (Alvarado-Mallart 2005; Joyner 1996; Martinez and AlvaradoMallart 1989; Raible and Brand 2004; Rhinn et al. 2006; Wurst and Bally-Cuif 2001). Initially the MHB is positioned along the anterior-posterior axis early within the neural plate by the opposing boundary created by mutual repression between the transcription factors otx 2 and gbx2 (Broccoli et al. 1999; Millet et al. 1999; Rhinn and Brand 2001; Simeone 2000). In contrast to other vertebrates, $g b x 1$ and not $g b x 2$ positions the MHB in zebrafish (Rhinn et al. 2009; Rhinn et al. 2005). At the end of gastrulation, a complex genetic network with several region-specific transcription factors such as $\operatorname{Pax} 2 / 5$ and En1/2, and the secreted molecules Wnt1 and Fgf8 are expressed at the Otx/Gbx interface (Rhinn and Brand 2001). The secreted signals from the isthmic organizer in turn determine the development of the surrounding mid and hindbrain tissue. Studies in different vertebrates show that three parallel signaling pathways, involving $\operatorname{Pax} 2 /$ pax 2.1, Wnt 1 and $\mathrm{Fgff}$, are activated independently at this interface during early embryonic stages (Figure 2 C (Canning et al. 2007; Lun and Brand 1998; Raible and Brand 2004; Reifers et al. 1998)). During later somitogenesis stages the three pathways become mutually dependent (Rhinn and Brand 2001). The expression of the region-specific transcription factors is later under the control of Fgf8, 17, 18 and Wnt1, 8b 10, secreted by the isthmic organizer itself (Raible and Brand 2004; Foucher et al. 2006; Buckles et al. 2004; Lekven et al. 2003 O'Hara, 2005 \#488). These factors are involved in regulating cell proliferation and patterning of the cerebellum as well as cell differentiation and maintenance.

\subsection{Positioning of the midbrain-hindbrain boundary and role of the isthmic organizer in establishing the cerebellar territories}

Initially the MHB is positioned along the anterior-posterior axis early within the neural plate by the opposing boundary between the transcription factors otx 2 and $g b x$. otx 2 is expressed in 
the forebrain and midbrain while $G b x$ is expressed in the hindbrain of vertebrates (Rhinn and Brand 2001; Simeone 2000). Studies in Xenopus, chick and mouse have shown that the mutual repression between $O t \times 2$ and $G b x 2$ are crucial for the correct positioning of the MHB within the neural tube (Broccoli et al. 1999; Katahira et al. 2000; Millet et al. 1999; Tour et al. 2002). In contrast to other studied vertebrates, gbxl positions the MHB in zebrafish (Rhinn et al. 2009). However, in accordance with studies in above mentioned studies in other vertebrates, the $\operatorname{otx} / g b x$ interface in zebrafish only positions the MHB along the anteriorposterior axis in the neural plate since the onset of other MHB genes are unchanged after $g b x 1$ loss- or gain-of-function experiments (Rhinn et al. 2009; Rhinn et al. 2005). Little is known about the signals that control the expression otx 2 and $g b x l$ but one such signal has been identified in zebrafish. During gastrulation Wnt8 is secreted from the blastoderm margin and it acts as posteriorizating signal during the initial subdivision of the neuroectoderm. Wnt8 is required for the onset of gbxl expression and the formation of the posterior border of otx 2 expression (Rhinn et al. 2005).

At the end of gastrulation, a complex genetic network with several region-specific transcription factors such as Pax2/5 and En1/2, and the secreted molecules Wnt1 and Fgf8 are expressed at the Otx/Gbx interface (Rhinn and Brand 2001). The secreted signals from the isthmic organizer in turn determine the development of the surrounding mid and hindbrain tissue. Studies in different vertebrates show that three parallel signaling pathways, involving Pax2/pax2.1, Wnt1 and Fgf8, are activated independently at this interface during early embryonic stages (Figure 3) (Canning et al. 2007; Lun and Brand 1998; Raible and Brand 2004; Reifers et al. 1998). During later somitogenesis stages the three pathways become mutually dependent (Rhinn and Brand 2001). The expression of the region-specific transcription factors is later under the control of Fgf8, 17, 18 and Wnt1, 8b 10, secreted by the isthmic organizer itself (reviewed in: (Raible and Brand 2004; Rhinn and Brand 2001)).

Fgf8 is the primary organizer molecule secreted by the isthmic organizer (Liu and Joyner 2001; Rhinn and Brand 2001; Wurst and Bally-Cuif 2001). $f g f 8$ is required for selfmaintenance of the MHB domain in zebrafish (Lun and Brand 1998; Reifers et al. 1998). fgf8 also controls the isthmic constriction (Brand et al. 1996). Furthermore, $f g f 8$ polarizes the midbrain and strongly influences the patterning of the cerebellar primordium (Picker et al. 1999; Reifers et al. 1998). In the fgf8 mutant acerebellar (ace) the isthmic constriction contain the MHB fails to form and the mutants completely lack a cerebellum (Reifers et al. 
1998). In the ace mutant the isthmic and cerebellar primordia acquire a more rostral mesencephalic identity (Jaszai et al. 2003; Reifers et al. 1998). Interestingly, the shift in identity of the cerebellar primordium does not take place if Otx function is abrogated in ace mutants (Foucher et al. 2006). Furthermore, the ability to generate different cerebellar cell types is not changed after a combined knockdown of otx and $f g f 8$ function in zebrafish embryos (Foucher et al. 2006).This suggests that $f g f 8$ is not instructive for the cerebellar territory nor for the differentiation of cerebellar cell types. However, Fgf signaling is crucial for controlling Otx expression in $\mathrm{r}$, proliferation, fusion and folding of the cerebellar primordium (Foucher et al. 2006). In addition, Fgf signaling and intact MHB tissue is necessary for repatterning and subsequent regeneration of the developing cerebellum (Jaszai et al. 2003; Koster and Fraser 2006). In zebrafish, Fgf signaling is post-transcriptionally regulated in the MHB by an miRNA, miR-9 (Leucht et al. 2008). miR-9 is broadly expressed in the zebrafish neural tube except for the MHB. miR-9 over expression largely eliminates the MHB and this phenotype is likely caused by miR-9 binding to $f g f 8$ and $f g f r l$ and subsequent down regulation of Fgf signaling. In addition, miR-9 also promote neurogenesis through the binding and down regulation of the basic helix-loop-helix transcription factors her 5and her 9 (Leucht et al. 2008). Interestingly, the POU-domain transcription factor Pou5f1 (previously Pou2) is necessary for the expression of MHB genes in zebrafish (Belting et al. 2001; Burgess et al. 2002; Reim and Brand 2002). Furthermore, Pou5fl has an additional role as an autonomous competence factor for cells in the hindbrain that responds to Fgf8 signaling (Reim and Brand 2002). In zebrafish wnt1, 3 and $10 b$ function redundantly at the MHB and they are required to maintain the expression of engrailed genes, pax2.1 and $f g f 8$ (Buckles et al. 2004; Lekven et al. 2003). Furthermore, the LIM homeodomain transcription factors $\operatorname{lmx} 1 b .1$ and $\operatorname{lmx} 1 b .2$ are required for wnt $1,3 a, 10 b, f g f 8$ and pax 8 expression at the MHB, and the maintenance of $\operatorname{lm} x 1 b$ expression is dependent on pax2.1 and Fgf signaling (O'Hara et al. 2005).

\subsection{Cerebellar germinal zones and progenitor domains}

The cerebellar neurons and glia originate from two principal germinal zones in the hindbrain, the rhombic lip (RL) and the ventricular zone (VZ). The VZ consists of the inner germinal zone that is located directly at the fourth ventricle, while the rhombic lip comprises the dorsal outer germinal zone that is located at the interface of the dorsal neural tube and the roof plate at the rim of the fourth ventricle (Figure 3, (Altman and Bayer 1997; Wingate 2001)). The 
rhombic lip is further divided into a rostral upper (cerebellar, also known as the germinal trigone) and a caudal lower (hindbrain) part (Altman and Bayer 1997). The upper rhombic lip (URL) encompasses the dorsal part of rhombomere 1 and the lower rhombic lip (LRL) comprises the rhombomeres 2-8 (Lumsden and Krumlauf 1996). In amniotes granule cell precursors migrate from the URL to the cerebellar surface where they transiently form a highly proliferative second germinal zone, the external granule layer (EGL).

During vertebrate development different cerebellar cell types are produced in a strict spatial and temporal order from increasingly committed progenitors (Figure 4) (Carletti and Rossi 2008; Wang and Zoghbi 2001). Excitatory neurons are generated by the RL and the inhibitory neurons are generated from the VZ (Hoshino et al. 2005). The transcription factor Ptfla marks progenitors of inhibitory neurons in the VZ, while the transcription factor Ato1 labels progenitors for excitatory cells in the RL and subsequent EGL (Ben-Arie et al. 1997; Hoshino et al. 2005; Pascual et al. 2007). Lineage tracing and fate map studies in chick and rodents have shown that the extra cerebellar and cerebellar long projecting neurons are produced firstly followed by diverse cerebellar interneurons (reviewed in (Carletti and Rossi 2008; Wang and Zoghbi 2001)). The deep cerebellar nuclei and other extra cerebellar nuclei (precerebellar nuclei) are generated prior to the genesis of the cerebellar cells in both the VZ and the RL (Hoshino et al. 2005). The generation of cerebellar inhibitory neurons follows an inside-out sequence from deep to superficial layers where the VZ generates the long projecting Purkinje neurons, Golgi/Lugaro cells, basket cells and stellate cells in a temporal succession (Carletti and Rossi 2008). In contrast to VZ, the generation of excitatory neurons from RL follows an outside-in sequence where unipolar brush cells are generated first followed by the generation of granule cells (Englund et al. 2006; Fink et al. 2006; Machold and Fishell 2005; Wang et al. 2005).

In zebrafish the cerebellar primordium becomes morphologically distinguishable during midsegmentation stages (16 hpf, Figure 4, (Langenberg et al. 2006)). Shortly after the formation of the cerebellar primordium the expression of the neural progenitor markers atohl and ptfla is detected in RL. During this time the restriction and folding of the neural tube at the MHB is initiated (Langenberg et al. 2006). The upper and lower rhombic lip parts are well recognizable one day after fertilization (Figure 3) and atohla-b expression is detected in the whole RL (Adolf et al. 2004; Kani et al. ; Kim et al. 1997; Koster and Fraser 2001), while ptfla expression is confined to the LRL (Elsen et al. 2008; Kani et al. ; Volkmann et al. 2008; 
Zecchin et al. 2004). Furthermore, this is also when the first cells start migrating out from the RL (see below, (Koster and Fraser 2001)). Ptfla expression is first detected shortly after 36 hpf in the cerebellar plate where its expressed ventricularly in close proximity to the fourth ventricle. The Ptfla expression is abutting a dorsal domain of atohl expression (Kani et al. ; Volkmann et al. 2008). Thus, at two days after fertilization, two distinct adjacent progenitor domains that anatomically and molecularly correspond to the URL and VZ domains of other vertebrates can be detected in the zebrafish cerebellar primordium (Figure 3). Intriguingly, the $\mathrm{VZ}$ and URL are partly maintained in juvenile and adult zebrafish (see adult neurogenesis chapter).

It is thought that the spatial patterning of progenitor domains in the embryonic RL corresponds to the functional domains in the mature cerebellum. In rodents the RL is patterned along its mediolateral axis. Granule cells that are generated rostrally generally end up medially while granule cells generated caudally end up in a lateral position ((Sgaier et al. 2007; Sgaier et al. 2005), Figure 5). Similarly, progenitors from different zones of the URL in zebrafish migrate along distinct paths to the corpus cerebelli, eminentia granularis and the caudal lobe CCe, EG LCa (Rieger et al. 2009; Volkmann et al. 2008). Granule cell progenitors in the medial part of the RL produce granule neurons in the corpus cerebelli while progenitors in the lateral part generate granule cells in the eminentia granularis. A stationary population of granule progenitors in the caudal part of the RL produces the granule cells in the caudal lobe (Volkmann et al. 2008). Interestingly, the spatial patterning of progenitors in the RL can be connected to distinct gene expression patterns. During granule cell development atoh 1 a expression is confined to the very anterior part of the RL while atohlc is restricted to the medial and caudal parts of the RL suggesting that the atohl genes could be involved in the spatial patterning of the progenitor domains in the RL (Chaplin et al. ; Kani et al.). Furthermore, the expression of markers such as: eomesa (tbr2), calbindin2, barhl1.1, barhl1.2 is different in granule cells in the caudal lobe compared to granule cells in the corpus cerebelli or eminentia granularis (Bae et al. 2009). Taken together, this suggests that distinct gene expression programmes control the generation of different granule cell progenitor domains and specific migratory patterns in the RL. It is unclear whether similar distinct progenitor domains also exist within the $\mathrm{VZ}$ in zebrafish. However, in rodents it is known that specific cell types are generated from different domains along the VZ (Altman and Bayer 1997). 


\subsection{Cerebellar neurogenesis}

The generation of cerebellar neurons starts around two days after fertilization in zebrafish. Initiation of layer formation starts at three days after fertilization when the first differentiated Purkinje cells are detected (Bae et al. 2009; Katsuyama et al. 2007; Volkmann et al. 2008). Granule cell production starts at two days after fertilization when granule cell precursors leave the URL and migrate in chain-like structures on top of the cerebellar primordium. (Adolf et al. 2004; Bae et al. 2009; Chaplin et al. ; Koster and Fraser 2001; Toyama et al. 2004; Volkmann et al. 2008). All the three cortical layers can be distinguished five days after fertilization.

The initial wave of delamination, migration and differentiation of cells from the cerebellar primordium (URL) starts at one day after fertilization (Koster and Fraser 2001). It was previously thought that URL derivates ultimately remain within the cerebellum, while LRL derivatives give rise to the precerbellar nuclei in the brain stem. However, an early rostroventral cell migration from the URL to brain stem nuclei outside the cerebellum was detected by in vivo imaging in zebrafish (Koster and Fraser 2001). Further examination of the rostroventral cell migration by different cell tracing approaches showed that the early migrating cells from the URL end up in tegmental nuclei located below the cerebellum (Kani et al. ; Volkmann et al.). Similarly, cell migration to the valvula cerbelli and the tegmental nuclei outside the cerebellum was detected during the first two days by following atohla:gfp protein perdurance or photo converted Kaede in cells originating from rostromedial tip of the URL (Kani et al.). In a complementary fate mapping approach using the wnt1:gal4-VP16-14 x UAS:GFP transgenic fish line that specifically labels atohla expressing cells in the rostromedial part of the URL showed that early migratory cells from the URL contribute to cholinergic and glutamergic neurons of the secondary gustatory/viscerosensory nucleus, nucleus isthmi and superior reticular nucleus (Volkmann et al.). Interestingly, the cells in the precerebellar nucleus lateralis valvulae are not derived from wntl:gal4-VP16-14 x UAS:GFP positive cells in the URL (Volkmann et al.). A similar rostro-ventral migratory pathway from the early URL to several different nuclei in tegmentum has been observed in chick and rodents (Wingate and Hatten 1999, Machold and Fishell 2005, Wang et al 2005). Furthermore, in mouse the first group of cells derived from atol expressing cells in the URL migrates rostro-ventrally and exits the cerebellum to form several different nuclei in the tegmentum (Machold and Fishell 2005; Wang et al. 2005; Wingate and Hatten 1999). In 
summary, the early generation of cells from the URL and their migratory pattern seem to be highly conserved in vertebrates.

Generation of cerebellar neurons starts around two days after fertilization in zebrafish. Initiation of layer formation starts at three days after fertilization when the first differentiated Purkinje cells are detected by the expression of markers such as Parvalbumin 7, aldocl, rora2, coe2 and gadl-2 (Bae et al. 2009; Elsen et al. 2009; Katsuyama et al. 2007; Volkmann et al. 2008). It was recently shown that hepatocyte growth factor signaling through its tyrosine kinase receptor Met is necessary for cerebellar proliferation, VZ progenitors and subsequent Purkinje cell development (Elsen et al. 2008). A mutagenesis screen has been performed to identify mutations that affect the neuronal development in zebrafish (Bae et al. 2009). Five day old larval fish stained with antibodies against Parvalbumin and Vglut1 that label Purkinje neurons and granule cell processes respectively, were screened for defects. Eight novel mutants with cerebellar specific phenotypes, such as the loss of Purkinje neurons and granule cells and the loss of only granule cells were found with this approach (Bae et al. 2009). Many of these mutants are still unidentified. Little is known about the development and specification of other inhibitory neuron types. The transcription factor olig2 labels progenitors, mature oligodendrocytes and eurydendroid cells in zebrafish (Bae et al. 2009; McFarland et al. 2008). During the development, the eurydendroid cells are derived from olig2:gfp expressing progenitors located in the caudal VZ and lateral regions of the URL. Interestingly, the olig2:gfp expressing eurydendroid cells appear to be derived from both ptfla and atohl expressing progenitors, although, they are later excitatory in nature (Kani et al.). Furthermore, antagonistic interplay between Hedgehog and Wnt signaling regulates the number and distribution of olig2:gfp expressing cells in the developing cerebellum. The absence of Hh signaling during early development increases the size of the olig2:gfp expressing cell population, while Wnt signaling is necessary for the development of the olig2:gfp cells (McFarland et al. 2008). It has been proposed that Hedgehog signaling may limit the range of Wnt signaling in the RL, which is necessary for the development of Olig2 expressing neurons (McFarland et al. 2008).

Granule cell production starts at two days after fertilization when granule cell precursors leave the URL. They rapidly migrate over long distance and start to differentiate (Koster and Fraser 2006; Volkmann et al. 2008). The differentiating granule cells express atohla-c, zicl, 2, 3, reelin, pax6a, tagl and neuroD1 (Adolf et al. 2004; Bae et al. 2009; Chaplin et al. ; Costagli 
et al. 2002; Elsen et al. 2008; Foucher et al. 2006; Jaszai et al. 2003; Koster and Fraser 2001; Toyama et al. 2004; Volkmann et al. 2008). The granule cells migrate in chain-like structures from the URL. Cadherin-2 is necessary to mediate chain formation and coordinate migratory behaviors of granule cells (Rieger et al. 2009). Granule cells expressing mature markers such as gabra6b and vglut1-2 are detected beneath the Purkinje cells five days after fertilization (Bae et al. 2009; Volkmann et al. 2008).

The general mode of the granule cell layer development show in zebrafish and teleost show intriguing evolutionary differences (figure 4). During development on amniotes granule cell precursors migrate from the URL to the cerebellar surface where they transiently form a highly proliferative second germinal zone, the external granule layer. Sonic hedgehog secreted from Purkinje neurons act as the major mitogenic signal for granule precursors in the external granule layer (Dahmane and Ruiz i Altaba 1999; Wechsler-Reya and Scott 1999). In contrast to amniotes, sonic hedgehog signaling and a prominent external granule cell layer is lacking in the developing and adult zebrafish cerebellum (Chaplin et al. ; Kaslin et al. 2009). Interestingly, the advent of a secondary zone of transient amplification (e.g. the external granule cell layer) seems to be an amniote specific developmental adaptation because shark, teleost fish and frogs lack an obvious external granule cell layer (Gona 1976; Chaplin et al. ; Butts et al. 2014a; Butts et al. 2014b). However, dividing intermediate granule precursors can be continuously detected in the zebrafish cerebellum although the amplification rate is very low (Kaslin et al. 2009). This suggests that the production of granule cells in zebrafish is more likely to be controlled on the level of the primary progenitors (Kaslin et al. 2009; Kaslin et al. 2013). Not much is known about signals that control the proliferation and differentiation of the cerebellar progenitors. However, Fgf signaling is required for the maintenance and proliferation of the adult cerebellar progenitors (Kaslin et al. 2009). In addition, sex differences in proliferation have been detected in the adult cerebellum (Ampatzis and Dermon 2007).

\section{Adult neurogenesis and regenerative potential of the zebrafish cerebellum}

In the zebrafish cerebellum the stem cell niche and its composition plays a critical role in regulating homeostatic growth and neural regeneration after injury (Kaslin et al. 2009; Kaslin et al. 2013; Kaslin et al. 2017; Lindsey et al. 2018b; Lindsey et al. 2018a). The zebrafish cerebellum proportionally grows more than other brain structures during juvenile stages. In 
particular, the main body of the cerebellum that contains granule cells expands significantly throughout life. However, the growth is selective and mainly granule cells are added while other core components of the cerebellar circuitry such as the Purkinje cells cease to be produced during the late phase of juvenile development Importantly, the growth is controlled at the level of neural stem and progenitor cells(Kaslin et al. 2009; Kaslin et al. 2013).

The cerebellar stem and progenitor cells arise early during embryonic development from a common domain of progenitors in the rhombic lip and form two distinct populations in the URL and VZ respectively inhabited by neuroepithelial-like and radial glia-like stem and progenitor cells (NE-SPC and VZ-SPC, Figure 4-5). In vivo imaging of the cerebellar stem cell niche from embryonic to adult stages showed that the niche is generated in a two-step process that initially involves morphogenetic movements and later tissue growth. Due to these processes rhombic lip progenitors and a small portion of the IVth ventricle, the cerebellar recessus, are displaced deep into the cerebellar tissue (Kaslin et al. 2009; Kaslin et al. 2013). In contrast, the cerebellar midline and the ventricle are lost as the two cerebellar hemispheres fuse in chick and rodents (Altman and Bayer 1997; Louvi et al. 2003; Sgaier et al. 2005). URL progenitors are maintained dorsal to the cerebellar recessus in the adult zebrafish while VZ-SPC are found ventral to the recessus (Figure 4). Remarkably, only the NE-SPC pool in URL persists in the adult and the ventricular VZ-SPC gradually become quiescent, or alternatively exhausted, during juvenile stages (Kaslin et al. 2009; Kaslin et al. 2013). Genetic lineage tracing showed that the loss of active VZ-SPC temporally overlap with the ceased production of neuronal subtypes such as the Purkinje cells. Furthermore, the quiescence of the ventricular VZ-SPC correlates with a transformation from radial morphology to flat epithelia similar to the transformation of radial glia to astrocytes observed in mammals (Kaslin et al. 2009; Kaslin et al. 2013; Kaslin et al. 2017).

NE-SPC and VZ-SPC are significantly activated after unilateral ablation of tissue in one of the cerebellar hemispheres (Figure 5 B) (Kaslin et al. 2017). Activation of the NE-SPC results in widespread replenishment of granule cells and re-growth of lost cerebellar tissue. Activation of the VZ-SPC results in very modest recovery of selected inhibitory inter-neurons and Bergmann glia. Early produced neuronal cell lineages such as the Purkinje and Eurydendroid cells don't regenerate well or at all. Intriguingly, the juvenile zebrafish cerebellum that harbours active VZ-SPC and NE-SPC can regenerate all major cell types including the Purkinje cells (Figure 5 C) (Kaslin et al. 2017).Taken together, only the cell 
types that are produced during homeostatic growth regenerate after injury in the cerebellum demonstrating the irreplaceable role of particular neural stem and progenitor cells such as the NE-SPC in growth and repair (Lindsey et al. 2018b). At present, evidence suggests that VZSPC cells play a minor role in adult cerebellar neurogenesis and in recovery after injury. Furthermore, the data suggests that VZ-SPC stem and progenitor cells over time may lose their potential in producing diverse cell lineages.

\section{Conclusions and future directions}

The recent advancements in development of genetic tools in zebrafish allows genetic labeling and manipulation of all major cerebellar cell types and circuits. This will enable new forward genetic screening approaches as well as the possibility to study specific neural circuits and their role in specific behaviors. Although the development and organization of the zebrafish cerebellum is now relatively well understood, some fundamental knowledge is still missing. Detailed maps of cerebellar afferent and efferent connections are crucial for new emerging interdisciplinary fields such as behavioral studies in combination with in vivo manipulation of neural circuits will be required. The cerebellar circuitry in zebrafish is well suited for manipulation by optogenetic tools since changes in circuit physiology and function can readily be visualized by in vivo imaging methods. Furthermore, it is possible to combine this approach with different behavioral paradigms. The temporal and spatial origin of specific cerebellar cell types during zebrafish development needs to be further characterized by genetic lineage tracing. It is, for example, not known when and where different subtypes of inhibitory neurons and glia originate during development. Furthermore, the persistence of diverse neural stem and progenitor cells in the cerebellum opens up new avenues to study the underlying mechanisms involved in stem cell maintenance and regulation. How these different stem and progenitors cells participate in neural repair is also important. Although cerebellar development and organization differs to some extent from the mammalian many of the events and molecular mechanism are highly conserved. Therefore zebrafish can be used as a model to study genes that are involved in human diseases by using the powerful tools and features specifically available for zebrafish. Morpholino based loss-of-function experiments in zebrafish provide a rapid and cost efficient way to test gene function and advancements in genome editing approaches such as CRISPR-Cas makes it simple to produce zebrafish with mutations corresponding to human disease mutations. Thus, zebrafish can beneficially be used to study basic mechanisms of cerebellar development, function, disease and repair. 


\section{Figure legends}

Figure 1. A. The vertebrate cerebellum consists of a major lobe, the corpus cerebelli (cerebellar corpus) and two bilateral lobes, the auricle (flocculus in tetrapods). In addition, mammals display a large lateral expansion of the corpus cerebelli, the neocerebellum. B. Schematic drawing of the zebrafish brain seen from the side and top. Light green illustrates the cerebellar corpus and the darker green the auricle. C. Schematic parasagittal overview of the zebrafish brain showing the major cerebellar parts and associated cerebellar structures. DF. Schematic anatomical overviews of the zebrafish cerebellum (adapted from Kaslin et al., 2009). D. Coronal view. E. Parasagittal view. F. Horisontal view. ACN=accessory cerebellar nuclei, $\mathrm{CCe}=$ cerebellar corpus, $\mathrm{CR}=$ cerebellar recessus, $\mathrm{CP}=$ choroid plexus, $\mathrm{CPN}=$ central pretectal nucleus, $\mathrm{EG}=$ eminentia granularis, $\mathrm{GL}=$ granular cell layer, $\mathrm{LCa}=$ caudal lobe of cerebellum, $\mathrm{ML}=$ molecular layer, $\mathrm{NLV}=$ nucleus lateralis valvulae, $\mathrm{NSPC}=$ neural stem and progenitor cells, $\mathrm{PCN}=$ paracommissural nucleus, $\mathrm{TL}=$ torus longintudinalis, $\mathrm{Va}=$ valvula cerebelli Vam=valvula cerebelli, molecular layer, Val= valvula cerebelli, granular cell layer

Figure 2. A. The zebrafish cerebellum has a simple laminar three layered architecture consisting of a molecular layer (ML), purkinje cell layer (PL) and a granule cell layer (GL). The granule layer is consisting of small densely packed excitatory granule cells and inhibitory Golgi neurons $(\mathrm{G})$. The Purkinje cell layer is inhabited with Purkinje neurons (PN), a specialized macroglia type, Bergmann glia (BG) and excitatory eurydendroid cells (E). The ML is mainly consisting of nerve fibers and scattered inhibitory stellate cells (S). Mossy and climbing fibers excite Purkinje and granule cells. Granule cell axons provide excitatory input to Purkinje cells and their dendrites as well as the Golgi and stellate cells. Purkinje cells inhibit eurydendroid cells. Eurydendroid cell axons project to various targets outside the cerebellum. Stellate cells provide inhibitory input to the dendrites of Purkinje cells and Golgi cells inhibit granule cells. Dendrites from granule cells together with Golgi cell axons and mossy fiber terminals form a specialized synaptic structure known as the glomerulus. B. Cerebellar afferents and efferents in teleost fish based on data compiled from Finger 1978, Wullimann et al., 1988, 1989, Ito and Yoshimoto 1990, Ikenaga 2002, Folguiera et al., 2006, Bae et al., 2009. $\mathrm{CM}=$ mammillary body, $\mathrm{CPN}=$ central pretectal nucleus, $\mathrm{DAO}=$ dorsal accessory optic nucleus, $\mathrm{Hd}=\mathrm{dorsal}$ zone of periventricular hypothalamus, $\mathrm{DTN}=\mathrm{dorsal}$ tegmental nucleus, IL=inferior lobe of the hypothalamus, $\mathrm{IO}=$ inferior olive, $\mathrm{LC}=$ locus coeruleus, $\mathrm{LX}=$ vagal lobe, $\mathrm{NI}=$ isthmic nucleus, $\mathrm{NLV}=$ nucleus lateralis valvulae, $\mathrm{NMLF}=$ nucleus of the medial longitudinal fascicle, $\mathrm{OR}=$ octavolateral region, 
$\mathrm{PCN}=$ paracommissural nucleus, $\mathrm{PPd}=$ dorsal periventricular pretectal nucleus, $\mathrm{PP}=$ posterior parvocellular preoptic nucleus, $\mathrm{RF}=$ reticular formation, $\mathrm{PL}=$ perilemniscal nucleus, $\mathrm{TL}=$ torus longintudinalis, $\mathrm{TS}=$ semicircular torus, $\mathrm{TeO}=$ optic tectum, $\mathrm{TPp}=$ periventricular nucleus of the posterior tuberculum, $\mathrm{VL}=$ ventrolateral thalamic nucleus, $\mathrm{VM}=$ ventromedial thalamic nucleus

Figure 3. Positioning of the midbrain-hindbrain boundary organizer in the neural plate of zebrafish. The interface between cells expressing otx and $g b x$ transcription factors marks the location in the neural plate where the midbrain-hindbrain boundary organizer forms. During gastrulation, Wnt8 is secreted by the blastoderm margin (red arrows). It is required for the initial subdivision of the neuroectoderm, including onset of the posterior gbxl (yellow) expression and establishment of the posterior border of otx2 (blue) expression. Towards the end of gastrulation, the $o t x 2$ and $g b x l$ expression domains are sharp and complementary. Grey area $=$ developing axial mesoderm. Light grey=yolk. Black arrows incdicate the mutually repressive interactions. B-C. Morphogenetic events of the cerebellar primordium. At $24 \mathrm{hpf}$ the midbrain-hindbrain boundary, midbrain structures and the cerebellar primordium are clearly distinguishable in the zebrafish embryo. C. At the end of gastrulation, a complex genetic network with several region-specific transcription factors and the secreted molecules Wnt1 and Fgf8 are expressed at the $o t x / g b x$ interface. The secreted signals from the isthmic organizer in turn determine the development of the surrounding mid and hindbrain tissue. D. Summary of the early morphogenetic events and the establishment of the cerebellar progenitor domains. A morphogenetic rotation of the cerebellar primordium takes place between $24-48 \mathrm{hpf}$ (blue arrow). From $36 \mathrm{hpf}$ onwards the dorsomedial part of the IVth ventricle is shifted anteriorly creating a dorsomedial extension of the IVth ventricle (red arrow). Ventricularly located progenitors (orange line) are found in the LRL of the hindbrain and in the VZ of the cerebellum. Cerebellar progenitors adjacent to the roof plate are induced to turn in to granule cell progenitors (URL, green line). (e). Schematic summary of tissue growth and displacement of the progenitor niche. Displacement of the URL progenitor niche through tissue growth begins around $7 \mathrm{dpf}$. During juvenile stages there is a massive expansion of the granule cell layer that displaces the ventricle. URL progenitors (green) are maintained dorsal to the cerebellar recesus in adult zebrafish while VZ derived progenitors and glia (orange) are found ventral to the recessus around the $\mathrm{IV}^{\text {th }}$ ventricle. (f) Schematic summary of the zebrafish cerebellar progenitor niche. Neural progenitors derived from the URL are maintained in the dorsomedial part of the cerebellum around a remnant of the IVth ventricle (the cerebellar recessuss). These progenitors give rise to granule neurons in a distinct outside-in fashion. 1. Polarized 
neuroepithelial-like stem and progenitor cells (green) are restricted to the midline of the dorsal cerebellum. The progenitors give rise to rapidly migrating granule precursors (dark green) that initially migrate dorsolaterally. During this initial phase the granule precursors still may proliferate. The granule precursors migrate in ventrolateral direction towards the GL and differentiate in to granule neurons. 2. A few glia with a radial morphology (light blue) are found close to the midline and they are used as scaffolds during the initial dorsal migration of granule precursors. 3. Bergmann glia-like cells are interspersed in the PL (dark blue). A low amount of Bergmann glia-like cells and inhibitory neurons (yellow) are generated from VZ progenitors. VZ progenitors are also found ventrally around the $\mathrm{IV}^{\text {th }}$ ventricle (see $\mathrm{E}$ ). $\mathrm{CB}=$ cerebellar primordium, $\mathrm{HB}=$ hindbrain, $\mathrm{GL}=$ granule cell layer, $\mathrm{IV}^{\text {th }} \mathrm{V}=\mathrm{IV}^{\text {th }}$ ventricle, $\mathrm{LRL}=$ lower rhombic lip, $\mathrm{MHB}=$ midbrain-hindbrain boundary, $\mathrm{ML}=$ molecular layer, $\mathrm{PL}=$ Purkinje cell layer, $\mathrm{URL}=$ upper rhombic lip, $\mathrm{VZ}=$ ventricular zone

Figure 4. Comparison of the life-long maintained neurogenic program in the zebrafish cerebellum and the cerebellar developmental program in mammals. 1. Ventricularly located VZ progenitors (orange) generate precursors (red) for inhibitory neurons and glia (yellow and blue). 2. In mammals progenitors (green) in the URL feed the EGL with granule cell precursors. In zebrafish no distinct EGL is discernable. 3. In mammals greatly amplifying granule cell precursors are found in the EGL. The granule cell precursors are initially tangentially migrating. In contrast a low level of amplification takes place in the zebrafish brain 4-5. Granule cell precursors become post-mitotic, differentiate and migrate ventrally into the GL. 6. In the mammalian cerebellum, the URL and EGL are exhausted of their progenitors whereas in zebrafish primary URL progenitors and some VZ progenitors are maintained in a specialized niche. $\mathrm{IV}^{\text {th }} \mathrm{V}=\mathrm{IV}^{\text {th }}$ ventricle, $\mathrm{CP}=$ choroid plexus, $\mathrm{CR}=$ cerebellar recessus, $\mathrm{EGL}=$ external granule layer, $\mathrm{GL}=$ granule cell layer, $\mathrm{ML}=$ molecular layer, $\mathrm{URL}=$ upper rhombic lip, $\mathrm{VZ}=$ ventricular zone

Figure 5. The diversity of stem cells is lost in the cerebellum during the transition from juvenile to adult and has an impact for homeostatic and regenerative neurogenesis. A. Cross section of the juvenile, young and mature zebrafish cerebellum showing change in stem and progenitor populations over time. The juvenile zebrafish maintains radial glia-like VZ stem and progenitor cells (VZ-SPC, labelled with red). The VZ-SPC are exhausted over time. Neuroepithelial-like stem and progenitor cells (NE-SPC, labelled in green) are maintained and active in the URL throughput life in zebrafish. Proliferating cell nuclear antigen (PCNA) labels all cycling cells in the cerebellum (Blue). B-C. The juvenile zebrafish maintains VZ- 
SPC and NE-SPC and is able to produce all major cell types during homeostasis and after injury (note well defined ML in injured right hemisphere). By contrast, the adult cerebellum does not produce all cell lineages and is not able to produce all cell types after injury, for example, Purkinje cells (Note absent ML and PL in injured right hemisphere). In the adult cerebellum, the VZ-SPCs become quiescent, whereas NE-SPCs are maintained continuously and contribute to granule cell neurogenesis. Significant regenerative cell production in GL seen in lesioned hemisphere. Incorporation of bromodeoxiuridine (BrdU, green) after injury labels produced cells, gamma butyric acid (GABA) labels inhibitory cells (blue) and ZebrinII (ZII) and Parvalbumin (PV) labels Purkinje cells (red). GL=granule cell layer, $\mathrm{ML}=$ molecular layer, $\mathrm{N}=$ neurons; $\mathrm{NE}=$ neuroepithelial-like cell, $\mathrm{PL}=$ Purkinje cell layer, $\mathrm{URL}=$ upper rhombic lip, $\mathrm{VZ}=$ ventricular zone

\section{References}

Adolf B, Bellipanni G, Huber V, Bally-Cuif L (2004) atoh1.2 and beta3.1 are two new bHLHencoding genes expressed in selective precursor cells of the zebrafish anterior hindbrain. Gene Expr Patterns 5 (1):35-41

Alonso JR, Arevalo R, Brinon JG, Lara J, Weruaga E, Aijon J (1992) Parvalbumin immunoreactive neurons and fibres in the teleost cerebellum. Anatomy and embryology 185 (4):355-361

Altman J, Bayer SA (1997) Development of the cerebellar system : in relation to its evolution, structure, and functions. CRC Press, Boca Raton

Alvarado-Mallart RM (2005) The chick/quail transplantation model: discovery of the isthmic organizer center. Brain research 49 (2):109-113

Ambrosi G, Flace P, Lorusso L, Girolamo F, Rizzi A, Bosco L, Errede M, Virgintino D, Roncali L, Benagiano V (2007) Non-traditional large neurons in the granular layer of the cerebellar cortex. Eur J Histochem 51 Suppl 1:59-64

Ampatzis K, Dermon CR (2007) Sex differences in adult cell proliferation within the zebrafish (Danio rerio) cerebellum. The European journal of neuroscience 25 (4):1030-1040

Bae YK, Kani S, Shimizu T, Tanabe K, Nojima H, Kimura Y, Higashijima S, Hibi M (2009) Anatomy of zebrafish cerebellum and screen for mutations affecting its development. Developmental biology 330 (2):406-426

Bell CC (2002) Evolution of cerebellum-like structures. Brain, behavior and evolution 59 (56):312-326

Bell CC, Han V, Sawtell NB (2008) Cerebellum-like structures and their implications for cerebellar function. Annual review of neuroscience 31:1-24

Belting HG, Hauptmann G, Meyer D, Abdelilah-Seyfried S, Chitnis A, Eschbach C, Soll I, Thisse C, Thisse B, Artinger KB, Lunde K, Driever W (2001) spiel ohne grenzen/pou2 is required during establishment of the zebrafish midbrain-hindbrain boundary organizer. Development (Cambridge, England) 128 (21):4165-4176

Ben-Arie N, Bellen HJ, Armstrong DL, McCall AE, Gordadze PR, Guo Q, Matzuk MM, Zoghbi HY (1997) Math1 is essential for genesis of cerebellar granule neurons. Nature 390 (6656):169-172

Brand M, Heisenberg CP, Jiang YJ, Beuchle D, Lun K, Furutani-Seiki M, Granato M, Haffter P, Hammerschmidt M, Kane DA, Kelsh RN, Mullins MC, Odenthal J, van Eeden FJ, 
Nusslein-Volhard C (1996) Mutations in zebrafish genes affecting the formation of the boundary between midbrain and hindbrain. Development (Cambridge, England) 123:179-190

Broccoli V, Boncinelli E, Wurst W (1999) The caudal limit of Otx2 expression positions the isthmic organizer. Nature 401 (6749):164-168

Buckles GR, Thorpe CJ, Ramel MC, Lekven AC (2004) Combinatorial Wnt control of zebrafish midbrain-hindbrain boundary formation. Mechanisms of development 121 (5):437-447

Burgess S, Reim G, Chen W, Hopkins N, Brand M (2002) The zebrafish spiel-ohne-grenzen (spg) gene encodes the POU domain protein Pou2 related to mammalian Oct4 and is essential for formation of the midbrain and hindbrain, and for pre-gastrula morphogenesis. Development (Cambridge, England) 129 (4):905-916

Butler A. B, Hodos W., (2005) Comparative vertebrate neuroanatomy. 2nd edn. John Wiley \& Sons, New York

Butts T, Hanzel M, Wingate RJ (2014a) Transit amplification in the amniote cerebellum evolved via a heterochronic shift in NeuroD1 expression. Development (Cambridge, England) 141 (14):2791-2795. doi:10.1242/dev.101758

Butts T, Modrell MS, Baker CV, Wingate RJ (2014b) The evolution of the vertebrate cerebellum: absence of a proliferative external granule layer in a non-teleost rayfinned fish. Evol Dev 16 (2):92-100. doi:10.1111/ede.12067

Canning CA, Lee L, Irving C, Mason I, Jones CM (2007) Sustained interactive Wnt and FGF signaling is required to maintain isthmic identity. Developmental biology 305 (1):276286

Carletti B, Rossi F (2008) Neurogenesis in the cerebellum. Neuroscientist 14 (1):91-100

Chaplin N, Tendeng C, Wingate RJ (2010) Absence of an external germinal layer in zebrafish and shark reveals a distinct, anamniote ground plan of cerebellum development. $\mathrm{J}$ Neurosci 30 (8):3048-3057

Costagli A, Kapsimali M, Wilson SW, Mione M (2002) Conserved and divergent patterns of Reelin expression in the zebrafish central nervous system. The Journal of comparative neurology 450 (1):73-93

Crook J, Hendrickson A, Robinson FR (2006) Co-localization of glycine and gaba immunoreactivity in interneurons in Macaca monkey cerebellar cortex. Neuroscience 141 (4):1951-1959

Dahmane N, Ruiz i Altaba A (1999) Sonic hedgehog regulates the growth and patterning of the cerebellum. Development (Cambridge, England) 126 (14):3089-3100

Delgado L, Schmachtenberg O (2008) Immunohistochemical localization of GABA, GAD65, and the receptor subunits GABAAalphal and GABAB1 in the zebrafish cerebellum. Cerebellum (London, England) 7 (3):444-450

Devor A (2000) Is the cerebellum like cerebellar-like structures? Brain research 34 (3):149156

Elsen GE, Choi LY, Millen KJ, Grinblat Y, Prince VE (2008) Zic1 and Zic4 regulate zebrafish roof plate specification and hindbrain ventricle morphogenesis. Developmental biology 314 (2):376-392

Elsen GE, Choi LY, Prince VE, Ho RK (2009) The autism susceptibility gene met regulates zebrafish cerebellar development and facial motor neuron migration. Developmental biology 335 (1):78-92

Englund C, Kowalczyk T, Daza RA, Dagan A, Lau C, Rose MF, Hevner RF (2006) Unipolar brush cells of the cerebellum are produced in the rhombic lip and migrate through developing white matter. J Neurosci 26 (36):9184-9195

Finger TE (1978) Efferent neurons of the teleost cerebellum. Brain Res 153 (3):608-614 
Finger TE (1983) Organization of the teleost cerebellum. In: Northcutt RG, Davis, R., G., (ed) Fish neurobiology, vol 1, Brain stem and Sense organs. University of Michigan press, Ann Arbor, pp 261-284

Fink AJ, Englund C, Daza RA, Pham D, Lau C, Nivison M, Kowalczyk T, Hevner RF (2006) Development of the deep cerebellar nuclei: transcription factors and cell migration from the rhombic lip. J Neurosci 26 (11):3066-3076

Folgueira M, Anadon R, Yanez J (2006) Afferent and efferent connections of the cerebellum of a salmonid, the rainbow trout (Oncorhynchus mykiss): a tract-tracing study. The Journal of comparative neurology 497 (4):542-565

Foucher I, Mione M, Simeone A, Acampora D, Bally-Cuif L, Houart C (2006) Differentiation of cerebellar cell identities in absence of Fgf signalling in zebrafish Otx morphants. Development (Cambridge, England) 133 (10):1891-1900

Gibbs MA, Northmore DP (1996) The role of torus longitudinalis in equilibrium orientation measured with the dorsal light reflex. Brain, behavior and evolution 48 (3):115-120

Gona AG (1976) Autoradiographic studies of cerebellar histogenesis in the

bullfrog tadpole during metamorphosis: the external granular layer. Journal of Comparative Neurology 165:77-87

Hans S, Kaslin J, Freudenreich D, Brand M (2009) Temporally-controlled site-specific recombination in zebrafish. PLoS ONE 4 (2):e4640

Hoshino M (2006) Molecular machinery governing GABAergic neuron specification in the cerebellum. Cerebellum (London, England) 5 (3):193-198

Hoshino M, Nakamura S, Mori K, Kawauchi T, Terao M, Nishimura YV, Fukuda A, Fuse T, Matsuo N, Sone M, Watanabe M, Bito H, Terashima T, Wright CV, Kawaguchi Y, Nakao K, Nabeshima Y (2005) Ptfla, a bHLH transcriptional gene, defines GABAergic neuronal fates in cerebellum. Neuron 47 (2):201-213

Housden BE, Muhar M, Gemberling M, Gersbach CA, Stainier DYR, Seydoux G, Mohr SE, Zuber J, Perrimon N (2016) Loss-of-function genetic tools for animal models: crossspecies and cross-platform differences. Nature Reviews Genetics 18:24. doi:10.1038/nrg.2016.118

Ikenaga T, Yoshida M, Uematsu K (2002) Efferent connections of the cerebellum of the goldfish, Carassius auratus. Brain, behavior and evolution 60 (1):36-51

Ikenaga T, Yoshida M, Uematsu K (2005) Morphology and immunohistochemistry of efferent neurons of the goldfish corpus cerebelli. The Journal of comparative neurology 487 (3):300-311

Ikenaga T, Yoshida M, Uematsu K (2006) Cerebellar efferent neurons in teleost fish. Cerebellum (London, England) 5 (4):268-274

Ito H, Yoshimoto M (1990) Cytoarchitecture and fiber connections of the nucleus lateralis valvulae in the carp (Cyprinus carpio). The Journal of comparative neurology 298 (4):385-399

Jaszai J, Reifers F, Picker A, Langenberg T, Brand M (2003) Isthmus-to-midbrain transformation in the absence of midbrain-hindbrain organizer activity. Development (Cambridge, England) 130 (26):6611-6623

Joyner AL (1996) Engrailed, Wnt and Pax genes regulate midbrain--hindbrain development. Trends Genet 12 (1):15-20

Kani S, Bae YK, Shimizu T, Tanabe K, Satou C, Parsons MJ, Scott E, Higashijima S, Hibi M (2010) Proneural gene-linked neurogenesis in zebrafish cerebellum. Developmental biology 343 (1-2):1-17

Kaslin J, Ganz J, Geffarth M, Grandel H, Hans S, Brand M (2009) Stem cells in the adult zebrafish cerebellum: initiation and maintenance of a novel stem cell niche. J Neurosci 29 (19):6142-6153. doi:10.1523/JNEUROSCI.0072-09.2009 
Kaslin J, Kroehne V, Benato F, Argenton F, Brand M (2013) Development and specification of cerebellar stem and progenitor cells in zebrafish: from embryo to adult. Neural development 8:9. doi:10.1186/1749-8104-8-9

Kaslin J, Kroehne V, Ganz J, Hans S, Brand M (2017) Distinct roles of neuroepithelial-like and radial glia-like stem and progenitor cells in cerebellar regeneration. Development (Cambridge, England) Apr 15;144(8):1462-1471. doi: 10.1242/dev.144907

Katahira T, Sato T, Sugiyama S, Okafuji T, Araki I, Funahashi J, Nakamura H (2000) Interaction between Otx 2 and $\mathrm{Gbx} 2$ defines the organizing center for the optic tectum. Mechanisms of development 91 (1-2):43-52

Katsuyama Y, Oomiya Y, Dekimoto H, Motooka E, Takano A, Kikkawa S, Hibi M, Terashima T (2007) Expression of zebrafish ROR alpha gene in cerebellar-like structures. Dev Dyn 236 (9):2694-2701

Kim CH, Bae YK, Yamanaka Y, Yamashita S, Shimizu T, Fujii R, Park HC, Yeo SY, Huh TL, Hibi M, Hirano $\mathrm{T}$ (1997) Overexpression of neurogenin induces ectopic expression of HuC in zebrafish. Neuroscience letters 239 (2-3):113-116

Koster RW, Fraser SE (2001) Direct imaging of in vivo neuronal migration in the developing cerebellum. Curr Biol 11 (23):1858-1863

Koster RW, Fraser SE (2006) FGF signaling mediates regeneration of the differentiating cerebellum through repatterning of the anterior hindbrain and reinitiation of neuronal migration. J Neurosci 26 (27):7293-7304

Laine J, Axelrad H (1994) The candelabrum cell: a new interneuron in the cerebellar cortex. The Journal of comparative neurology 339 (2):159-173

Langenberg T, Dracz T, Oates AC, Heisenberg CP, Brand M (2006) Analysis and visualization of cell movement in the developing zebrafish brain. Dev Dyn 235 (4):928-933

Lekven AC, Buckles GR, Kostakis N, Moon RT (2003) Wntl and wnt10b function redundantly at the zebrafish midbrain-hindbrain boundary. Developmental biology 254 (2):172-187

Leucht C, Stigloher C, Wizenmann A, Klafke R, Folchert A, Bally-Cuif L (2008) MicroRNA9 directs late organizer activity of the midbrain-hindbrain boundary. Nature neuroscience 11 (6):641-648

Li M, Zhao L, Page-McCaw PS, Chen W (2016) Zebrafish Genome Engineering Using the CRISPR\&\#x2013;Cas9 System. Trends in Genetics 32 (12):815-827. doi:10.1016/j.tig.2016.10.005

Lindsey BW, Douek AM, Loosli F, Kaslin J (2018a) A Whole Brain Staining, Embedding, and Clearing Pipeline for Adult Zebrafish to Visualize Cell Proliferation and Morphology in 3-Dimensions. Front Neurosci 11 (750). doi:10.3389/fnins.2017.00750

Lindsey BW, Hall ZJ, Heuze A, Joly JS, Tropepe V, Kaslin J (2018b) The role of neuroepithelial-like and radial-glial stem and progenitor cells in development, plasticity, and repair. Prog Neurobiol 11 (17):30185-30185

Liu A, Joyner AL (2001) Early anterior/posterior patterning of the midbrain and cerebellum. Annual review of neuroscience 24:869-896

Louvi A, Alexandre P, Metin C, Wurst W, Wassef M (2003) The isthmic neuroepithelium is essential for cerebellar midline fusion. Development (Cambridge, England) 130 (22):5319-5330

Lumsden A, Krumlauf R (1996) Patterning the vertebrate neuraxis. Science (New York, NY 274 (5290):1109-1115

Lun K, Brand M (1998) A series of no isthmus (noi) alleles of the zebrafish pax2.1 gene reveals multiple signaling events in development of the midbrain-hindbrain boundary. Development (Cambridge, England) 125 (16):3049-3062 
Machold R, Fishell G (2005) Math1 is expressed in temporally discrete pools of cerebellar rhombic-lip neural progenitors. Neuron 48 (1):17-24

Martinez S, Alvarado-Mallart RM (1989) Rostral Cerebellum Originates from the Caudal Portion of the So-Called 'Mesencephalic' Vesicle: A Study Using Chick/Quail Chimeras. The European journal of neuroscience 1 (6):549-560

Matsui H, Namikawa K, Babaryka A, Koster RW (2014) Functional regionalization of the teleost cerebellum analyzed in vivo. Proceedings of the National Academy of Sciences of the United States of America 111 (32):11846-11851. doi:10.1073/pnas.1403105111

McFarland KA, Topczewska JM, Weidinger G, Dorsky RI, Appel B (2008) Hh and Wnt signaling regulate formation of olig2 + neurons in the zebrafish cerebellum. Developmental biology 318 (1):162-171

Meek J (1983) Functional anatomy of the tectum mesencephali of the goldfish. An explorative analysis of the functional implications of the laminar structural organization of the tectum. Brain Res 287 (3):247-297

Meek J (1992) Comparative aspects of cerebellar organization. From mormyrids to mammals. European journal of morphology 30 (1):37-51

Meek J (1998) Holosteans and teleosts. In: Nieuwenhuys R. TDH, J., Nicholson C. (ed) The central nervous system of vertebrates Springer, Berlin,

Meek J, Yang JY, Han VZ, Bell CC (2008) Morphological analysis of the mormyrid cerebellum using immunohistochemistry, with emphasis on the unusual neuronal organization of the valvula. The Journal of comparative neurology 510 (4):396-421

Millet S, Campbell K, Epstein DJ, Losos K, Harris E, Joyner AL (1999) A role for Gbx2 in repression of Otx2 and positioning the mid/hindbrain organizer. Nature 401 (6749):161-164

Mugnaini E, Sekerkova G, Martina M The unipolar brush cell: A remarkable neuron finally receiving the deserved attention. Brain research reviews

Murakami T, Morita Y (1987) Morphology and distribution of the projection neurons in the cerebellum in a teleost, Sebastiscus marmoratus. The Journal of comparative neurology 256 (4):607-623

Nieuwenhuys R, Pouwels E, Smulders-Kersten E (1974) The neuronal organization of cerebellar lobe $\mathrm{C} 1$ in the mormyrid fish Gnathonemus Petersii (teleostei). Zeitschrift fur Anatomie und Entwicklungsgeschichte 144 (3):315-336

Northmore DP, Williams B., Vanegas H. (1983) The teleostean torus longitudinalis: Responses

related to eye movements, visuotopic

mapping, and functional relations with the optic

tectum. J Comp Physiol A 150:39-50

O'Hara FP, Beck E, Barr LK, Wong LL, Kessler DS, Riddle RD (2005) Zebrafish Lmx1b.1 and Lmx1b.2 are required for maintenance of the isthmic organizer. Development (Cambridge, England) 132 (14):3163-3173

Pascual M, Abasolo I, Mingorance-Le Meur A, Martinez A, Del Rio JA, Wright CV, Real FX, Soriano E (2007) Cerebellar GABAergic progenitors adopt an external granule cell-like phenotype in the absence of Ptfla transcription factor expression. Proceedings of the National Academy of Sciences of the United States of America 104 (12):5193-5198

Picker A, Brennan C, Reifers F, Clarke JD, Holder N, Brand M (1999) Requirement for the zebrafish mid-hindbrain boundary in midbrain polarisation, mapping and confinement of the retinotectal projection. Development (Cambridge, England) 126 (13):2967-2978

Pouwels E (1978) On the development of the cerebellum of the trout, Salmo gairdneri. IV. Development of the pattern of connectivity. Anatomy and embryology 153 (1):55-65 
Raible F, Brand M (2004) Divide et Impera--the midbrain-hindbrain boundary and its organizer. Trends in neurosciences 27 (12):727-734

Reifers F, Bohli H, Walsh EC, Crossley PH, Stainier DY, Brand M (1998) Fgf8 is mutated in zebrafish acerebellar (ace) mutants and is required for maintenance of midbrainhindbrain boundary development and somitogenesis. Development (Cambridge, England) 125 (13):2381-2395

Reim G, Brand M (2002) Spiel-ohne-grenzen/pou2 mediates regional competence to respond to Fgf8 during zebrafish early neural development. Development (Cambridge, England) 129 (4):917-933

Rhinn M, Brand M (2001) The midbrain--hindbrain boundary organizer. Curr Opin Neurobiol $11(1): 34-42$

Rhinn M, Lun K, Ahrendt R, Geffarth M, Brand M (2009) Zebrafish gbx1 refines the midbrain-hindbrain boundary border and mediates the Wnt8 posteriorization signal. Neural development 4:12

Rhinn M, Lun K, Luz M, Werner M, Brand M (2005) Positioning of the midbrain-hindbrain boundary organizer through global posteriorization of the neuroectoderm mediated by Wnt8 signaling. Development (Cambridge, England) 132 (6):1261-1272

Rhinn M, Picker A, Brand M (2006) Global and local mechanisms of forebrain and midbrain patterning. Curr Opin Neurobiol 16 (1):5-12

Rieger S, Senghaas N, Walch A, Koster RW (2009) Cadherin-2 controls directional chain migration of cerebellar granule neurons. PLoS biology 7 (11):e1000240

Scott EK (2009) The Gal4/UAS toolbox in zebrafish: new approaches for defining behavioral circuits. Journal of neurochemistry 110 (2):441-456

Sgaier SK, Lao Z, Villanueva MP, Berenshteyn F, Stephen D, Turnbull RK, Joyner AL (2007) Genetic subdivision of the tectum and cerebellum into functionally related regions based on differential sensitivity to engrailed proteins. Development (Cambridge, England) 134 (12):2325-2335

Sgaier SK, Millet S, Villanueva MP, Berenshteyn F, Song C, Joyner AL (2005) Morphogenetic and cellular movements that shape the mouse cerebellum; insights from genetic fate mapping. Neuron 45 (1):27-40

Simeone A (2000) Positioning the isthmic organizer where Otx2 and Gbx2meet. Trends Genet $16(6): 237-240$

Simmich J, Staykov E, Scott E (2012) Zebrafish as an appealing model for optogenetic studies. Progress in brain research 196:145-162. doi:10.1016/B978-0-444-59426$6.00008-2$

Takacs J, Markova L, Borostyankoi Z, Gorcs TJ, Hamori J (1999) Metabotrop glutamate receptor type 1a expressing unipolar brush cells in the cerebellar cortex of different species: a comparative quantitative study. Journal of neuroscience research 55 (6):733748

Tour E, Pillemer G, Gruenbaum Y, Fainsod A (2002) Gbx2 interacts with Otx2 and patterns the anterior-posterior axis during gastrulation in Xenopus. Mechanisms of development 112 (1-2):141-151

Toyama R, Gomez DM, Mana MD, Dawid IB (2004) Sequence relationships and expression patterns of zebrafish zic2 and zic5 genes. Gene Expr Patterns 4 (3):345-350

Volkmann K, Chen YY, Harris MP, Wullimann MF, Koster RW (2010) The zebrafish cerebellar upper rhombic lip generates tegmental hindbrain nuclei by long-distance migration in an evolutionary conserved manner. The Journal of comparative neurology 518 (14):2794-2817

Volkmann K, Rieger S, Babaryka A, Koster RW (2008) The zebrafish cerebellar rhombic lip is spatially patterned in producing granule cell populations of different functional compartments. Developmental biology 313 (1):167-180 
Wang VY, Rose MF, Zoghbi HY (2005) Math1 expression redefines the rhombic lip derivatives and reveals novel lineages within the brainstem and cerebellum. Neuron 48 (1):31-43

Wang VY, Zoghbi HY (2001) Genetic regulation of cerebellar development. Nat Rev Neurosci 2 (7):484-491

Wechsler-Reya RJ, Scott MP (1999) Control of neuronal precursor proliferation in the cerebellum by Sonic Hedgehog. Neuron 22 (1):103-114

Wingate RJ (2001) The rhombic lip and early cerebellar development. Curr Opin Neurobiol $11(1): 82-88$

Wingate RJ, Hatten ME (1999) The role of the rhombic lip in avian cerebellum development. Development (Cambridge, England) 126 (20):4395-4404

Wullimann MF (1997) The central nervous system. In: Evans D. H, Claiborne J., B., (ed) In Physiology of Fishes, vol Vol. II. CRC Press, Boca Raton,

Wullimann MF, Northcutt RG (1988) Connections of the corpus cerebelli in the green sunfish and the common goldfish: a comparison of perciform and cypriniform teleosts. Brain, behavior and evolution 32 (5):293-316

Wullimann MF, Northcutt RG (1989) Afferent connections of the valvula cerebelli in two teleosts, the common goldfish and the green sunfish. The Journal of comparative neurology 289 (4):554-567

Wurst W, Bally-Cuif L (2001) Neural plate patterning: upstream and downstream of the isthmic organizer. Nat Rev Neurosci 2 (2):99-108

Xue HG, Yang CY, Yamamoto N (2008) Afferent sources to the inferior olive and distribution of the olivocerebellar climbing fibers in cyprinids. The Journal of comparative neurology 507 (3):1409-1427

Zecchin E, Mavropoulos A, Devos N, Filippi A, Tiso N, Meyer D, Peers B, Bortolussi M, Argenton F (2004) Evolutionary conserved role of ptfla in the specification of exocrine pancreatic fates. Developmental biology 268 (1):174-184 
A Teleost fish

Auricle

Corpus cerebelli

D

F
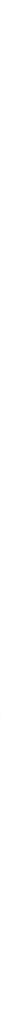

B

Cerebellum

C

C Cerebellum
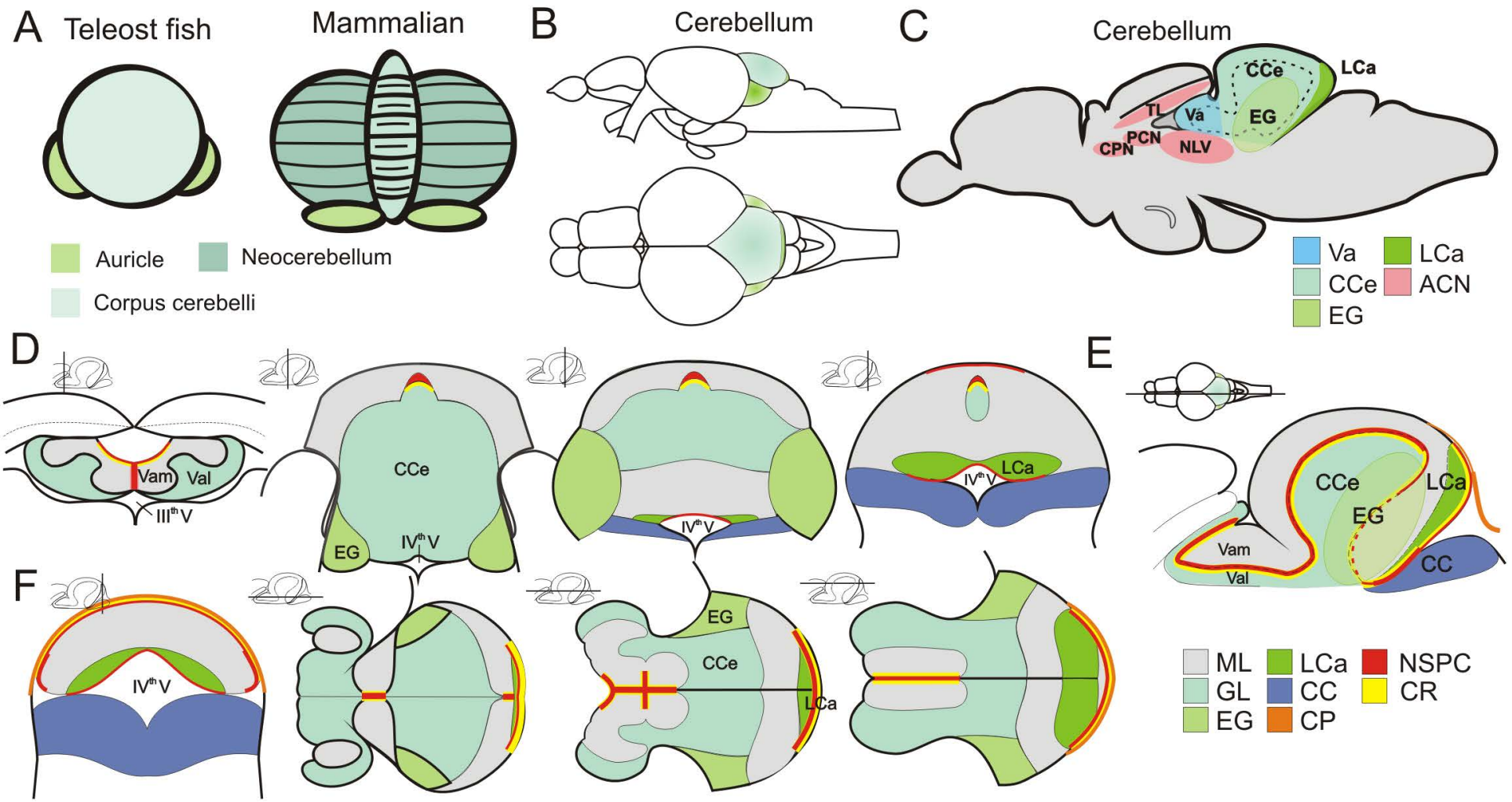

E
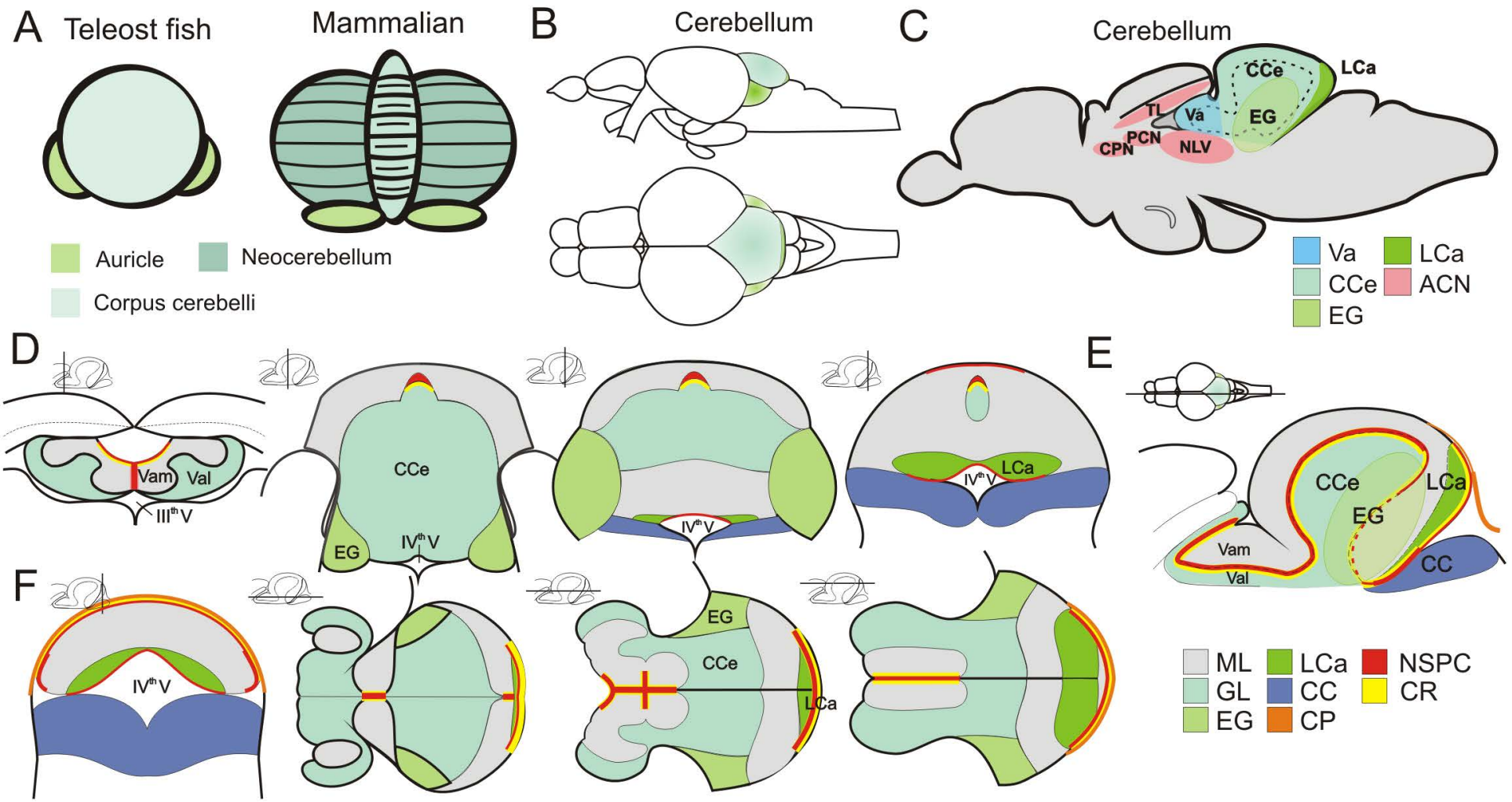


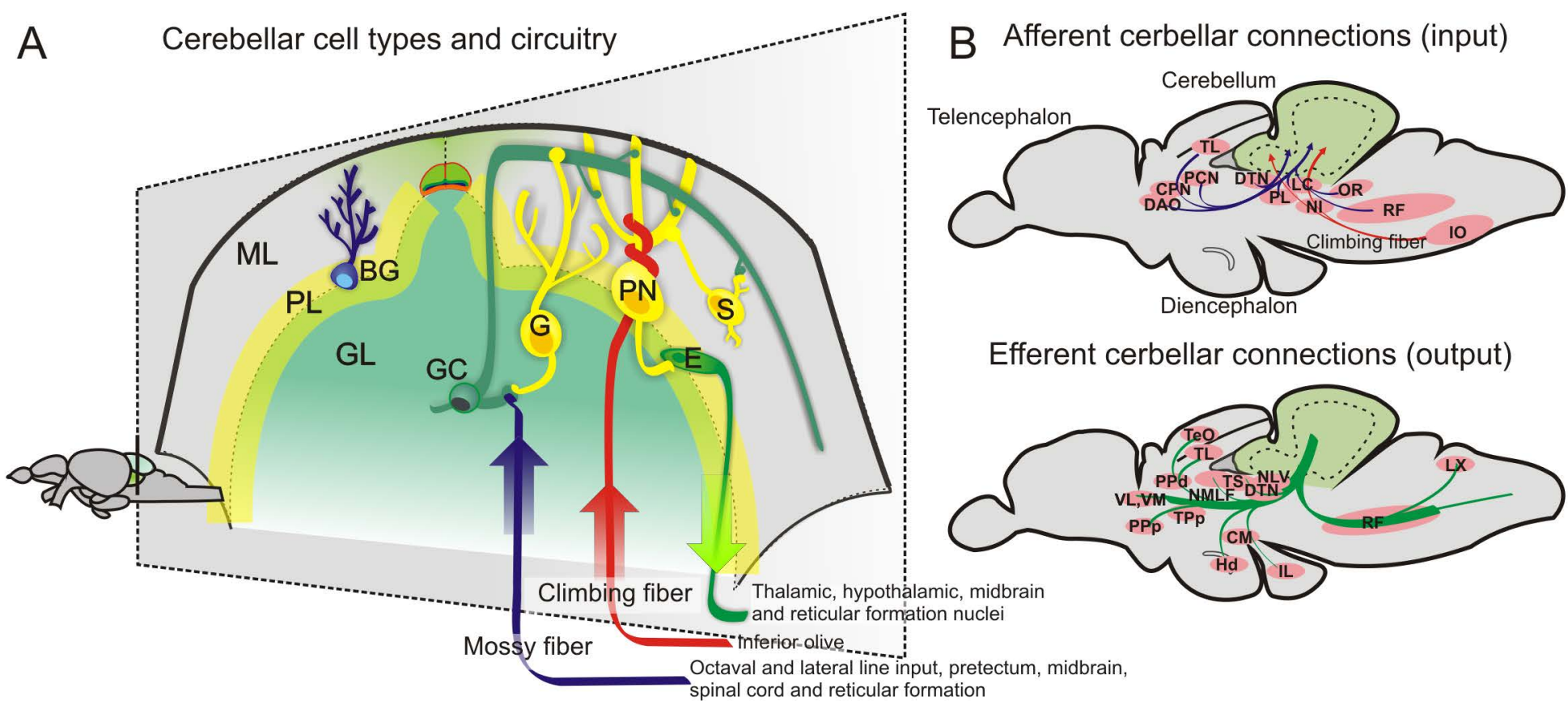


A

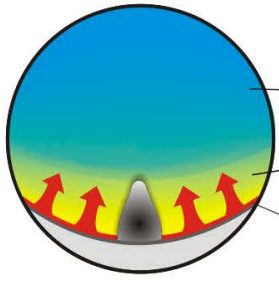

$60 \%$ epiboly

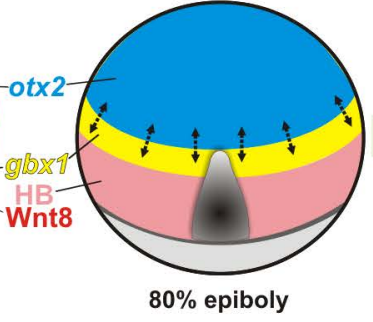

$80 \%$ epiboly
B

C

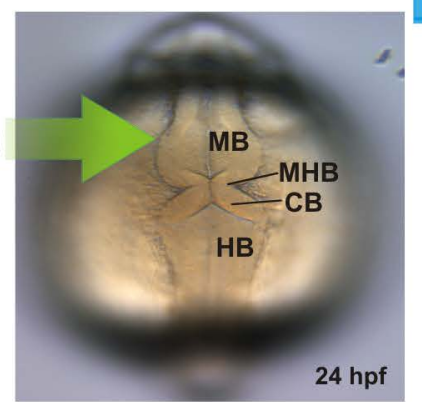

D
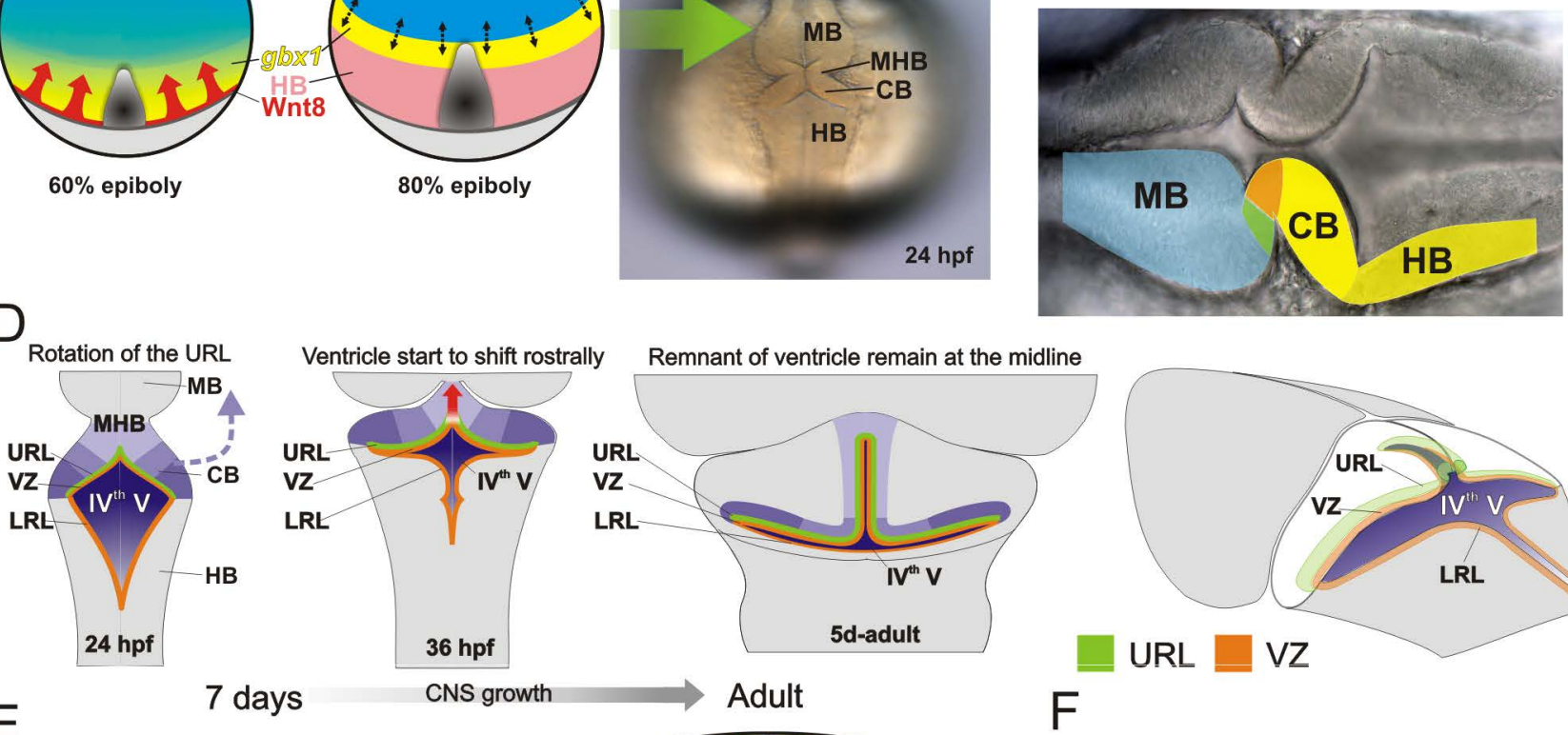

E

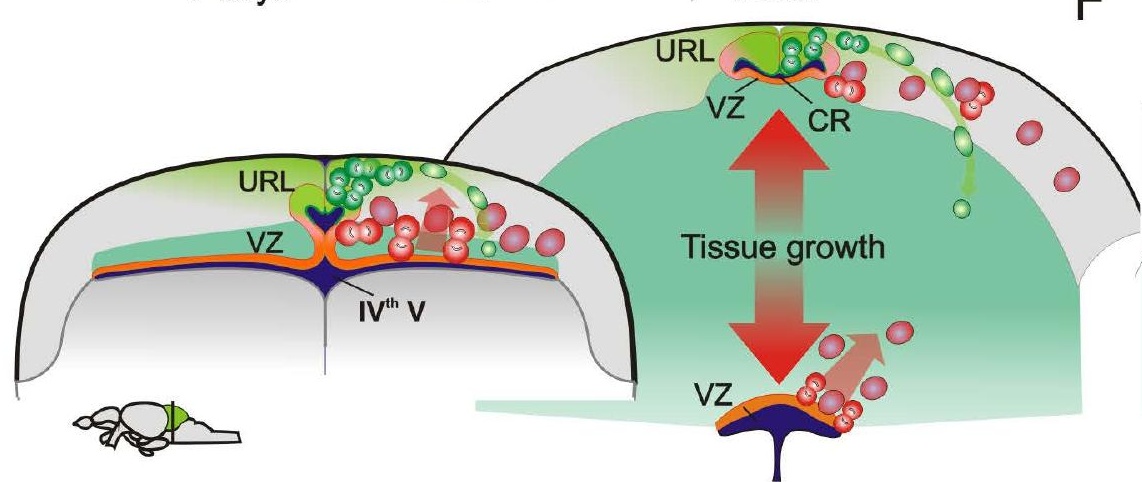

URL $\square$ VZ

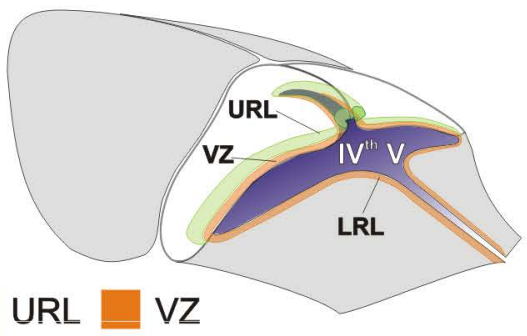

F

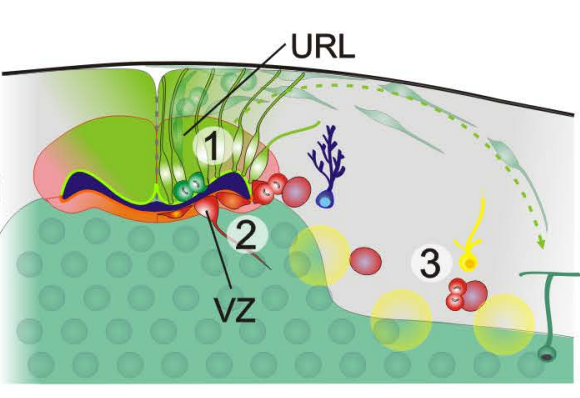





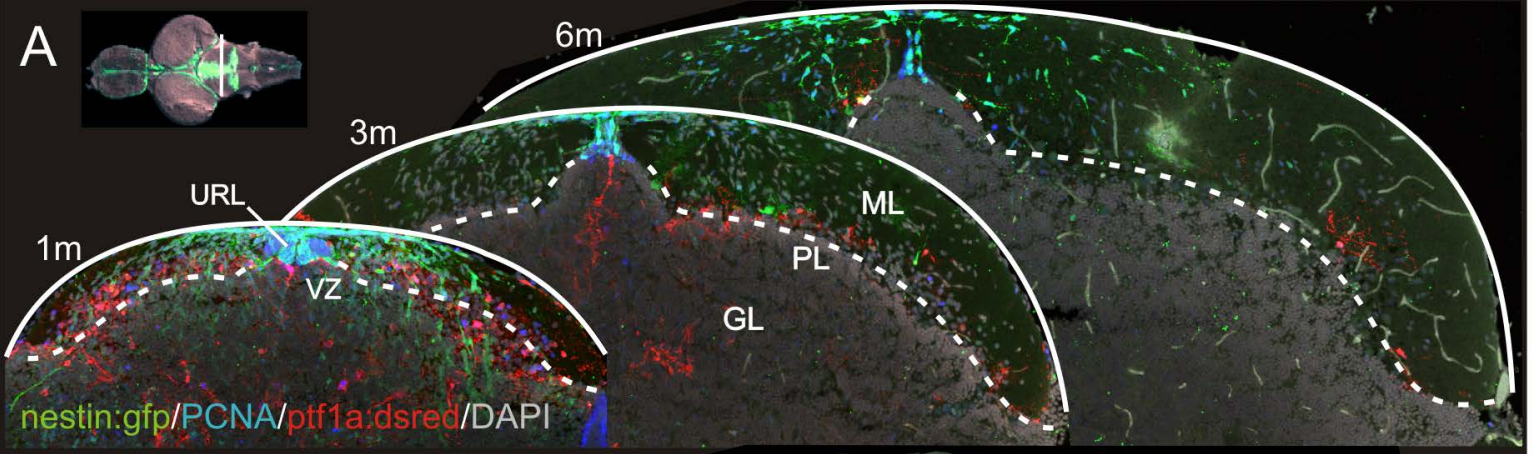

\section{B}

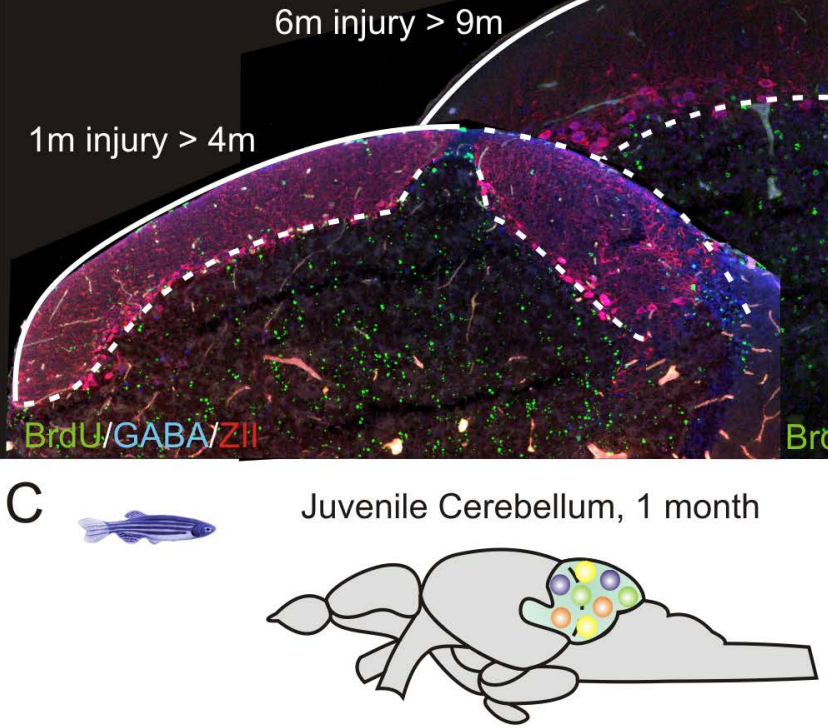

High level stem cell activity. Multiple stem cell types are active and diverse repertoire of cell types are produced. Multiple subtypes of neurons are produced after injury
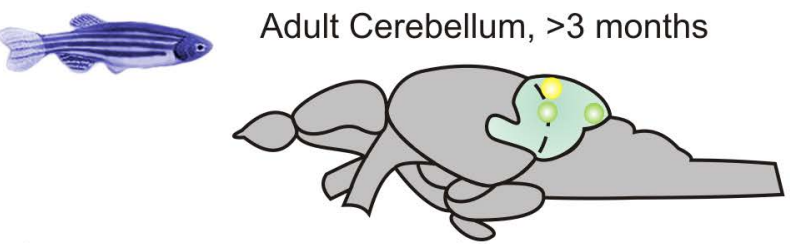

Significant stem cell activity but quiescence of distinct stem cells. Limited types of cells are produced during homeostasis and after injury
BrdUYGABAIPV

\section{VZ-SPC}
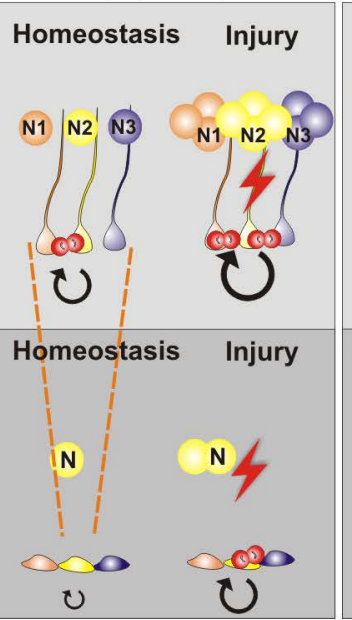

NE-SPC

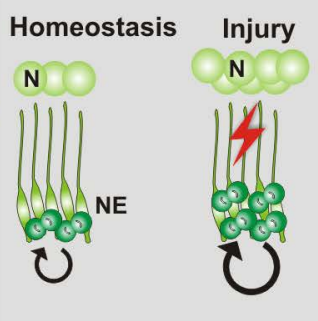

Homeostasis Injury

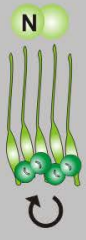

N

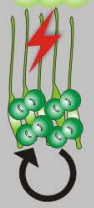

